\title{
Appendicitis in pregnancy: case report in a navy medical center of Mexico City
}

\begin{abstract}
Acute appendicitis represents the most common non-obstetric surgical emergency during pregnancy, the most important clinical feature is abdominal pain in the right lower quadrant. Imaging studies can be used for diagnosis, where ultrasound and magnetic resonance imaging are mostly recommended. Timely diagnosis can prevent complications including fetal loss and preterm delivery. The case report orients the surgeon and obstetrician to make decisions in patients with this pathology.
\end{abstract}

Keywords: appendicitis, pregnancy, appendectomy
Volume 7 Issue 6 - 202I

\author{
Erika Valencia Mejía, Cèsar Rodriguez Villàn, \\ Yanet Fermin Aldama, Fernando Martínez \\ Gónzalez, Josè Eduardo Serratos Garduño, \\ Cristian de la Rosa Ramos \\ Obstetrics Department, UNAM, Mexico
}

\author{
Correspondence: Valencia Erika, Obstetrics Department, \\ UNAM, Mexico, Tel 4421718512. \\ Email erikavalencia.35@hotmail.com
}

Received: November 13, 202| | Published: December 07, 2021

\section{Introduction}

Acute appendicitis is the most common obstetric emergency during pregnancy. ${ }^{1,2}$ International reports range from 1-1500 to 1:2000 cases. In Mexico there are different reports since 1:982 of pregnant women with appendicitis reported by the Hospital Angeles Mexico, likewise the National Institute of Perinatology reports 1:8770 and the Spanish Hospital of Mexico 1:1279. ${ }^{3}$ The highest rate of occurrence of appendicitis during pregnancy has been reported during the 1 st and 2nd trimester. ${ }^{3,4}$

It is of great importance to make a timely diagnosis of appendicitis during pregnancy since it decreases the probability of complications when the evolution is less than 24 hours. ${ }^{3}$ Among the main signs and symptoms are nausea, anorexia, and vomiting, which can occur in pregnant patients without appendicitis, ${ }^{5}$ so pain in the right lower quadrant is the most important sign for diagnosis. ${ }^{6}$ According to the literature, the position of the appendix may vary during the different trimesters of pregnancy, however, the main location is the right lower quadrant, as in the general population. ${ }^{7}$

Due to the location, differential diagnoses that may occur during pregnancy, which are less frequent, should be considered, including right diverticulitis, adnexal torsion, spontaneous perforation of the appendix due to neoplastic process. ${ }^{8}$

The imaging studies that are recommended in pregnant patients are ultrasound, since it is easily accessible and does not present a risk of ionizing radiation, ${ }^{6}$ as well as magnetic resonance, which presents a sensitivity of $91.8 \%$ and a specificity of $97.9 \% .{ }^{1}$ Both imaging studies can be performed in any trimester of pregnancy. ${ }^{9}$ On the other hand, computed tomography is recommended as a last option, since there are different studies that have related it to teratogenesis and cancer in childhood. $^{7}$

The complications to be avoided are fetal loss, which occurs mainly in the first trimester of pregnancy, ${ }^{9}$ where it has been associated mainly in young patients under 18 years of age, ${ }^{4}$ preterm delivery in the third trimester and perforation in any trimester. ${ }^{9}$ The treatment of choice is appendectomy, where it has been reported that there is no difference between open appendectomy and laparoscopic appendectomy with respect to preterm delivery. ${ }^{2}$

\section{Case report}

Female patient, 22 years old, housewife, resides in Acuexcomac, State of Mexico. She denies chronic degenerative diseases; obstetric history of 2 pregnancies, both resolved by cesarean section secondary to premature rupture of membranes and preeclampsia; (last cesarean section 2017). Current pregnancy in the last trimester estimated by clinic, with poor obstetric control.

She arrives into the hospital because of uterine activity that intensified 3 hours prior to her arrival, presenting sudden abdominal pain in the lower quadrants, disabling, preventing ambulation, nausea and partial tolerance to food, no vomiting, denies transvaginal leakage or irritative symptoms of urinary tract.

On physical examination the patient was conscious, oriented, with adequate color, adequate hydration status, neck, and cardiopulmonary status without compromise. Abdomen globose by pregnant uterus with uterine fundus of $29 \mathrm{~cm}$, fetal heart rate of $148 \mathrm{bpm}$, longitudinal, cephalic, back to the right, free, fetal movements are palpated, valsalva and Tarnier negative, clean glove, posterior cervix $3 \mathrm{~cm}$ dilated, $30 \%$ effacement, without data of neurovascular compromise.

Her vital signs with blood pressure of $120 / 70 \mathrm{mmHg}$, heart rate of 80 beats per minute, respiratory rate of 22 breaths per minute, and temperature of $37{ }^{\circ} \mathrm{C}$. Laboratory studies were performed with results of leukocytes 9.2. In addition, a 20-minute cardiotocographic recording was performed: moderate variability, baseline of $150 \mathrm{bpm}$ with irregular uterine activity, reactive; likewise, ultrasound scan showed a single live intrauterine product, cephalic, FHR 145 bpm, gestational age 33.5 weeks of gestation, ILA $11 \mathrm{~cm}$, PM $4.5 \mathrm{~cm}$, placenta anterior grade II. It was decided to terminate the pregnancy due to risk of dehiscence of previous hysterorrhaphy due to iterative cesarean section.
After analysis, the following diagnoses were established:
a. Pregnancy of 33-34 weeks of gestation by ultrasonography.
b. Iterative cesarean section.
c. Preterm labor in the latent phase.
d. Hysterorrhaphy involvement.
e. Maternity satisfied. 
Regional anesthesia was performed, Kerr cesarean section, during the inspection of the parietocolic slides prior to closure, was obtained a grade II appendicitis, so a pouchet appendectomy was performed by the surgery service. The diagnosis of acute appendicitis was confirmed by pathology study with a report of reactive lymphoid hyperplasia with macroscopic description: cecal appendix of 5.4 x $0.7 \mathrm{~cm}$, smooth, light brown, soft with narrow lumen. Representative sections are included in a capsule; microscopic description: appendiceal mucosa without epithelial atypia, submucosal lymphoid tissue with large follicles of reactive germinal centers, normal muscular and serous layers.

Female newborn of $1.9 \mathrm{~kg}$ (4.18 pounds), Apgar 7/8, Silverman 4, Capurro 33 weeks of gestation was obtained.

Favorable evolution, patient discharged 48 hours after surgery. Newborn delivered 2 weeks after cesarean section due to prematurity (Figure 1).
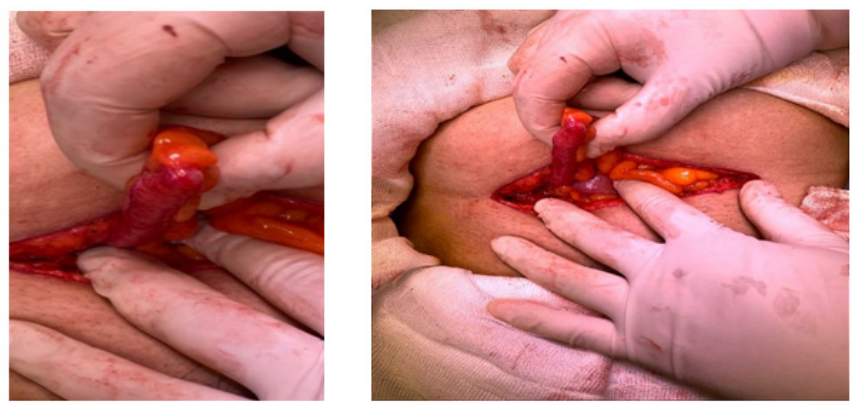

Figure I Hallazgos transoperatorios. Apéndice cecal.Apendicitis grado II.

\section{Discussion}

Acute appendicitis in pregnancy is a surgical emergency, which, according to the literature, occurs in the first and second trimester of pregnancy, however, in the clinical case it occurred in the third trimester. ${ }^{3,4}$

Among the main symptoms are nausea, vomiting and abdominal pain, ${ }^{5,6}$ which were present in our patient, however, the clinical picture of appendicitis was masked by labor. On the other hand, abdominal pain was present in the region of previous hysterorrhaphy, so it is considered that abdominal pain in appendicitis during pregnancy may be modified by maternal physiology. ${ }^{7}$

Laboratories during pregnancy may present leukocytosis, ${ }^{9}$ so it is unreliable to base the diagnosis based only on laboratory studies, however, in the clinical case presented, the patient presented studies in normal parameters.

Regarding treatment, recent meta-analysis studies have shown that there is no difference between open appendectomy and laparoscopy. ${ }^{10}$ Regarding the clinical case presented, open appendectomy was performed since it was presented as a transoperative finding during the Kerr type cesarean section. The patient's evolution was favorable during the following 48 hours, so it was decided to discharge her from the hospital.

\section{Conclusions}

Acute appendicitis during pregnancy is a surgical emergency. It is an infrequent pathology, which occurred in the third trimester of pregnancy, which is rare. This pathology can be difficult to diagnose because the symptoms are similar to those presented during pregnancy. Similarly, the inflammatory process generated by appendicitis can trigger labor, making it even more difficult to diagnose. Nausea, vomiting and oral intolerance may lead to suspect an appendicular condition when patients do not yet present uterine activity triggered by the inflammatory process. This pathology is important because it can compromise the life of the mother and the fetus. For a timely diagnosis, clinical suspicion is necessary, as well as the support of imaging studies, among which ultrasound and magnetic resonance imaging are preferred.

\section{Acknowledgments}

None

\section{Conflicts of interest}

Authors declare no conflict of interest

\section{Funding}

None.

\section{References}

1. Kave M, Parooie F, Salarzaei M. Pregnancy and appendicitis: a systematic review and meta-analysis on the clinical use of MRI in diagnosis of appendicitis in pregnant women. World J Emerg Surg. 2019;14(1):37.

2. Lee SH, Lee JY, Choi YY, et al. Laparoscopic appendectomy versus open appendectomy for suspected appendicitis during pregnancy: a systematic review and updated meta-analysis. BMC Surg. 2019;19(1):41.

3. Kuba EOB. Acute appendicitis during pregnancy. Experience at the Angeles Mexico Hospital. Cir Gen. 2006;4.

4. Arévalo Pereira KM del P, Giancarlo Buitrago Gutiérrez G, Moyano Guacaneme JS, et al. Prognosis factors associated with premature delivery in women undergoing appendectomy during pregnancy in a middleincome country. Rev Colomb Cir. 2020;27;35(1):22-31.

5. Hodjati H, Kazerooni T. Location of the appendix in the gravid patient: a re-evaluation of the established concept. Int $J$ Gynecol Obstet. 2003;81(3):245-247.

6. Bolivar Rodriguez MA, Cazares Aguilar MA, Fierro Lopez R. Acute Appendicitis During Pregnancy: Report of 4 cases. Ginecol Obstet Mex. 2014;30;82:337-343.

7. Selzer DJ, Stefanidis D. Surgical Emergencies in the Pregnant Patient. Adv Surg. 2019;53:161-77.

8. Kunovsky L, Kala Z, Mitas L, et al. Rare cases imitating acute appendicitis: Three case reports and a review of literature. Rozhl Chir. 2017;6.

9. Weinstein MS, Feuerwerker S, Baxter JK. Appendicitis and Cholecystitis in Pregnancy. Clin Obstet Gynecol. 2009;52(4):586-96.

10. Augustin G, Boric M, Barcot O, et al. Discordant outcomes of laparoscopic versus open appendectomy for suspected appendicitis during pregnancy in published meta-analyses: an overview of systematic reviews. Surg Endosc. 202;34(10):4245-4256. 